\title{
Analytical investigation in the impact interaction of a vibration digger with the body of the root during its extraction from the soil
}

\author{
Adamchuk V. ${ }^{1}$, Bulgakov V. ${ }^{2}$, Kuvachov V. ${ }^{3}$, Holovach I. ${ }^{4}$, Ihnatiev Ye. ${ }^{5}$, Yaremenko V. ${ }^{6}$ \\ ${ }^{1} N S C$ «Institute of mechanization and electrification of agriculture» \\ 11 Vokzalna Str., Hlevakha township, Vasylkiv district, Kyiv oblast, 08631, Ukraine \\ $2,4,6$ National university of life and environmental sciences of Ukraine \\ 15 Heroiv Oborony Str., Kyiv, 03041, Ukraine \\ 3, 5 Dmytro Motornyi Tavria state agrotechnological university \\ 18 B. Khmelnytskyi Ave., Melitopol, Zaporizhzhia oblast, 72312, Ukraine

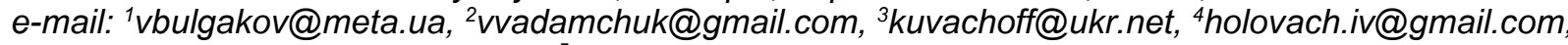 \\ 5yevhen.ihnatiev@tsatu.edu.ua \\ ORCID: ${ }^{1} 0000-0003-0358-7946,{ }^{2} 0000-0003-3445-3721,{ }^{4} 0000-0003-1387-4789,{ }^{5} 0000-0003-0315-1595$
}

The purpose. To substantiate rational constructive and kinematic parameters of the vibrating digger at its shock interaction with the root of sugar beet under the condition of its undamaging during digging from the soil. Methods. Theoretical research was conducted using the basic principles of higher mathematics and theoretical mechanics, in particular the theory of impact. Numerical calculations and graphical dependencies were obtained using a PC based on the developed and standard programs. Results. The shock interaction of the vibrating digging working body with the body of the sugar beet root at one point (asymmetric impact) is considered. Based on the developed equivalent scheme and application of the general theory of impact, a mathematical model of the impact interaction of the vibrating digger of the beet harvester with the body of the root, which is firmly connected with dry and hard soil, is built. Analytical expressions are obtained to determine the shock impulse, as well as the maximum allowable frequency of oscillations of the working body and reduced to the point of impact of its mass, provided that the root is not damaged. Based on analytical expressions, calculations were performed on a PC and graphical dependencies were created of the maximum allowable oscillation frequency of the vibrating digger and reduced to the point of impact of its mass on the amplitude of oscillations and translational velocity for a wide range of values of these parameters. Conclusions. With the increasing frequency of vibration of the vibrating digger in the range of $7.5-20.3 \mathrm{~Hz}$ and the speed of translational movement in the range of $1.4-2.2 \mathrm{~m} / \mathrm{s}$ the value of the reduced to the point of impact of its mass tends to decrease and varies within $1.51-0.63 \mathrm{~kg}$ with an amplitude of oscillations of 0.016 $\mathrm{m}$. The maximum allowable frequency of oscillations of the vibrating digger with increasing amplitude of its oscillations decreases sharply, the same as with the increasing speed of translational motion. Thus, for the consolidated mass of the vibrating digger $1.5 \mathrm{~kg}$ and the depth of its motion in the soil $0.10 \mathrm{~m}$ with increasing amplitude of oscillations in the range of $0.008-0.024 \mathrm{~m}$ and the speed of translational movement in the range of $1.4-2.2 \mathrm{~m} / \mathrm{s}$ the maximum allowable frequency varies between $15.7-4.0 \mathrm{~Hz}$. For the depth of motion of the vibrating digging working body $0.08 \mathrm{~m}$, it varies in the range of $33.0-10.0 \mathrm{~Hz}$.

Key words: beet, asymmetric impact, maximum allowable frequency, amplitude, depth of motion, translational speed.

$$
\text { DOI: https://doi.org/10.31073/agrovisnyk202011-06 }
$$

The necessary condition to ensure the quality of the technological process of vibratory root excavation is their intactness. Obviously, the greatest probability of damage to the root crops and even their breaking takes place in the presence of the impact interaction of the digging working organ with the root body, especially when working in dry and solid ground. The specified shock interaction occurs during the first contact of the working body with the root, which is firmly connected with the surrounding soil, due to the speed of progressive motion Kopach and the speed of oscillatory motion of the working body itself. During such a contact within a fairly short period of time there is a significant shock pulse, which may lead to the breaking of the root.

Therefore there is an actual scientific and technical problem to investigate theoretically specified shock interaction that will allow to define rational constructive and kinematic parameters of the digging out working body from conditions of intactness of root crops at the specified shock interaction at their vibratory digging.

Analysis of recent research and publications. Fundamental theoretical studies of the process of vibratory root excavation were carried out in the works [1-3]. Some experimental studies of this process are briefly discussed in monographs [4, 5]. In works [6-9] the general questions of the mechanized harvesting of root crops are covered, the designs of digging working bodies, results of theoretical and experimental researches of processes of digging of root crops are resulted.

However, the impact interaction of the vibratory digging working device with the root body fixed in the soil is not considered here. Only in works [4,5] experimental results of the shock interaction of the pendulum copier with the root body are given. In this paper we study the impact interaction of the vibratory digging organ at the 
moment of its first contact with the body of the root, that is, at the moment of impact of one of the ploughshares on the root of sugar beet.

Research Aim. Justification of rational structural and kinematic parameters of the vibrating digger at its impact interaction with sugar beet root when digging out of the soil, provided its damage.

Materials and methods. Theoretical studies were conducted using the basic principles of higher mathematics and theoretical mechanics, in particular the theory of impact. Numerical calculations and graphical dependencies were obtained using a PC based on developed and standard programs.

Results and discussion. Obviously, in the progressive movement of the vibratory digger along the line of root crops, the first percussive contact of the digging working body with the root can occur with two digging ploughshares at the same time and with only one digging ploughshare. In the first case, there is a symmetrical impact on the root-foot at the side of the implement (two points), in the second case - an asymmetrical impact (one point). Since the roots are often located with some deviation from the axis of the row, it is more likely that there may be an impact interaction of the root with the implement at one point, that is, with one of the ploughshares. This is the case and is discussed in this article.

As a result of fluctuations ploughshares loosened soil between ploughshares and root crops do not accumulate, then, thanks to the progressive movement of the digger and oscillating movements of the working body, the first contact of root crops with the working body will be shock, and the impact can occur either directly or through a fairly thin layer of soil. As is known, the impact is characterized by a significant shock pulse. Since the impact impulse has a certain final value and operates for a very short period of time, the impact force will be large enough to significantly exceed the value of all other forces acting on the root for the same period of time. And since the root is still firmly anchored in the soil, especially dry and hard, there is a danger of its destruction or rupture during vibration excavations. Of course, the harder and drier the soil, the above concepts are adequate to the real impact interaction process.

For analytical study of the impact process we will firstly make an equivalent scheme of shock interaction of the vibratory digging working device with the root body at the first contact of the working device on the root (Fig. 1). For what we will present the vibratory working device in the form of two wedges $A_{1} B_{1} C_{1}$ and $A_{2} B_{2} C_{2}$, each of which in space is tilted at angles $\alpha, \beta, \gamma$, and which are installed in such a way that a working channel is formed, the back part of which narrows (Fig. 1). These wedges make vibratory movements in the longitudinal-vertical plane, the direction of progressive movement of the vibratory digging working device is shown by arrow.

We will consider that the impact interaction of the root, which is approximated by a cone-shaped body, occurs only with the surface of the wedge $A_{1} B_{1} C_{1}$ at the point $K_{1}$ (fig. 1).

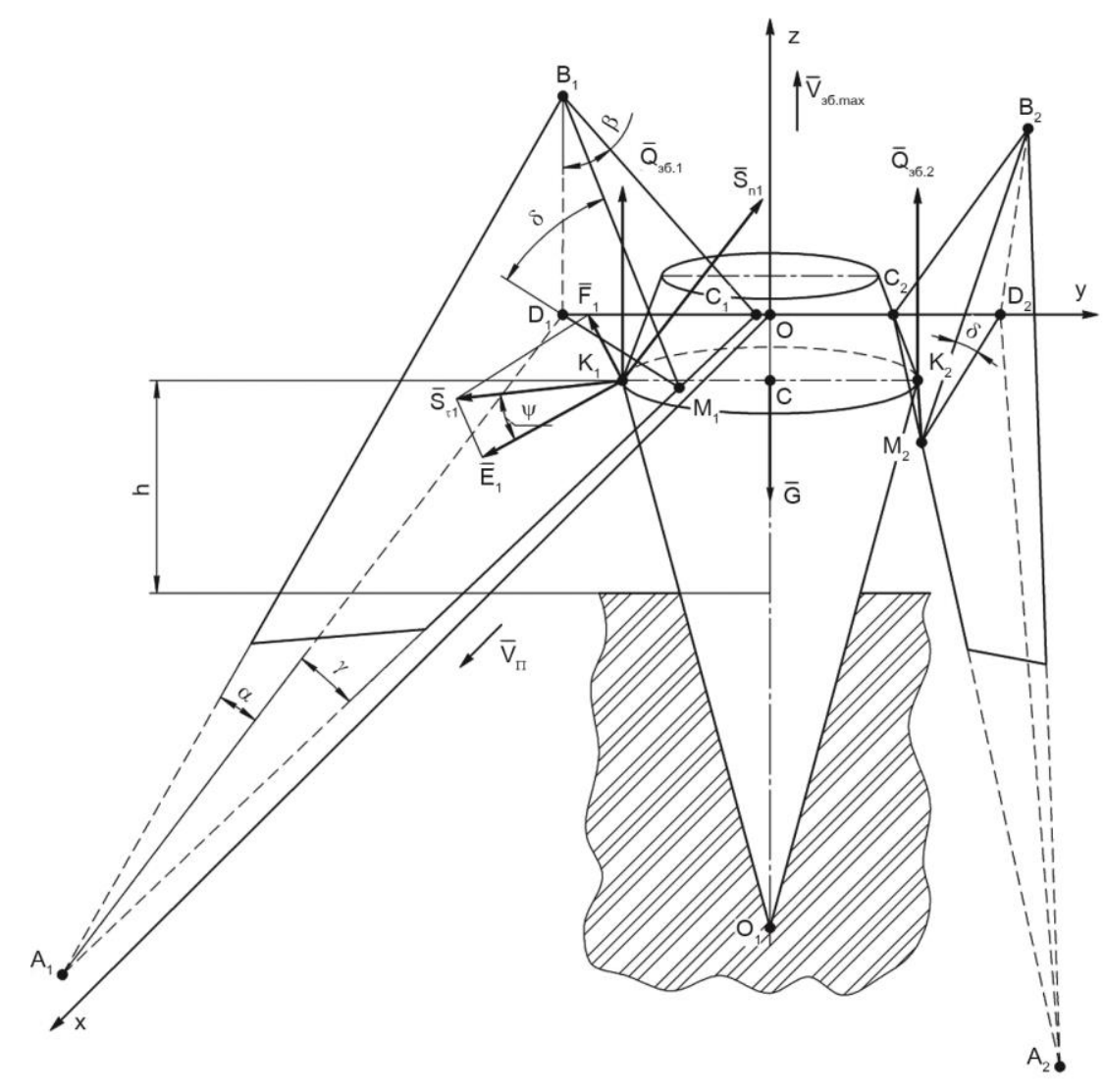

Fig. 1. Equivalent scheme of shock interaction of vibratory digging working device with the root body, fixed in the soil, in one point 
And the impact contact can take place either directly or through a thin layer of soil between the surface of the wedge and the root.

To study the specified shock interaction, let's enter a rectangular Cartesian coordinate system Oxyz, center $O$ is in the middle of the narrowed channel digger, $O x$ axis coincides with the direction of progressive motion of the digger, $\mathrm{Oz}$ axis has the direction upwards, and $\mathrm{Ox}$ axis is directed to the right side of the digger (fig. 1). Let's show the forces arising from the impact interaction of vibrating working device with the root body (fig. 1).

Let the vibrating working device act as a vertical perturbing force $\bar{Q}_{3 \text {. }}$, which changes for the harmonious law of such a review:

$$
Q_{\text {зб. }}=H \cdot \sin \omega t
$$

where $H$ - outrageous amplitude, $\mathrm{H} ; \omega$ - rotary frequency of disturbance, $\mathrm{s}^{-1} ; t$-current time, $\mathrm{s}$.

The specified outrage is provided simultaneously from both ploughshares, and therefore in the scheme it is represented by two components $\bar{Q}_{3 \overline{1} .1}$ and $\bar{Q}_{3 \sigma .2}$, which are applied respectively to the points of contact $K_{1}$ and $K_{2}$, that are at a distance of $h$ from the lower edge of the ploughshare (a layer of unplowed soil).

Therefore, there is the following ratio:

$$
Q_{30.1}=Q_{36.2}=\frac{1}{2} H \cdot \sin \omega t .
$$

It should be noted that it is the perturbing force that carries out the process of vibratory digging of roots.

However, it is known that only shock impulse plays an essential role in impact interaction. The impulses of all forces acting on the root at impact are practically equal to zero, i.e. infinitely small values [10, 11]. That is, they are infinitely small values. Therefore, they may not be shown on the equivalent scheme of shock interaction.

Therefore on the equivalent scheme we will show only shock impulses - normal and tangent. Normal shock pulse $\bar{S}_{n 1}$ appended at point $K_{1}$ and directed along the normal to the working surface of the ploughshare, i.e. planes $A_{1} B_{1} C_{1}$. Tangential shock pulse $\bar{S}_{\tau 1}$ is located in the plane (working surface) of the ploughshare and is tangential to the side surface of the root at the point of contact $\mathrm{K}_{1}$.

On an equivalent circuit, a tangential shock pulse $\bar{S}_{\tau 1}$ is broken down into $\bar{F}_{1}$, perpendicular line $A_{1} C_{1}$, and part $\bar{E}_{1}$, parallel line $A_{1} C_{1}$ (fig. 1).

The magnitude of the shock pulse can be different depending on the speed of oscillatory motion of the working device in the vertical plane at the moment of its shock contact with the root. Moreover, since the root has a conical shape, then the movement of the vibratory working device downwards the vertical component of the shock pulse is actually absent. In this case, the shock pulse will arise only from the progressive movement of the digger.

Let the oscillating motion of the vibrating working body be performed by the following harmonic law:

$$
z_{k}=-a \cdot \cos \omega t,
$$

where $z_{k}$ - deviations of the working device from the horizontal axis around which the oscillation occurs, $\mathrm{m}$; $\omega$-working device oscillation frequency, $\mathrm{s}^{-1} . a$-oscillation amplitude of the working device, $\mathrm{m}$.

Then the speed $V_{3 \overline{0}}$. of the oscillating motion of the working device as the first derivative of the function (3) by time at any point in time $t$ will be equal:

$$
V_{\text {зб. }}=a \cdot \omega \cdot \sin \omega t \text {, }
$$

and the maximum value of this speed will be:

$$
V_{\text {зб.max }}=a \cdot \omega .
$$

So we need to investigate the case of a shock interaction when the shock pulse is maximal. This is exactly the case when at the moment of impact contact of the vibratory excavating organ on the root, the working organ moves upwards at the maximum speed $V_{36 \text {.max }}$.

For the analytical study of the impact process under consideration, the theorem on the change in the amount of impact movement was applied [12]:

$$
m(\bar{U}-\bar{V})=\bar{S}_{n 1}+\bar{S}_{\tau 1},
$$

where $\bar{V}$ - the speed of the working device to impact; $\bar{U}$ - the working device speed after impact; $m-$ is reduced to the point of impact the mass of the implement.

On the basis of the theorem on change of quantity of movement at impact (expression (6)), in conditions of non-smoothing of a root body at its shock interaction with vibratory digging out working body, we have 
received value of admissible maximum speed $V_{3 б . \max }$ oscillating movement of the vibratory digging working organ:

$$
V_{\text {зб.max }}=\frac{1}{\tan \beta}\left(\frac{\left[M_{32}\right] t_{y \partial .}}{A \cdot B \cdot h \cdot m(1+\varepsilon)}-V_{\mathrm{\Pi}} \tan \gamma\right),
$$

where $\left[M_{32}\right]$ - acceptable bending moment for the body of the root, at which there is no breaking of the

$$
\begin{aligned}
& \text { root; } \sqrt{\left(\frac{2 \tan \gamma}{\sqrt{\tan ^{2} \gamma+1+\tan ^{2} \beta}}+2 f \cos \psi \cos \gamma-2 f \sin \psi \cos \delta \sin \gamma\right)^{2}+} \\
& \sqrt{+\left(\frac{2}{\sqrt{\tan ^{2} \gamma+1+\tan ^{2} \beta}}-2 f \cos \psi \sin \gamma-2 f \sin \psi \cos \delta \cos \gamma\right)^{2}}=A \\
& \frac{\sqrt{\tan ^{2} \gamma+1+\tan ^{2} \beta}}{\tan ^{2} \beta+f \sin \psi \sin \delta \cdot \tan \beta \sqrt{\tan ^{2} \gamma+1+\tan ^{2} \beta}+1-} \\
& \overline{-(f \cos \psi \sin \gamma+f \sin \psi \cos \delta \cos \gamma) \times} \\
& \times \sqrt{\tan ^{2} \gamma+1+\tan ^{2} \beta}+\tan ^{2} \gamma+(f \cos \psi \cos \gamma-f \sin \psi \cos \delta \sin \gamma) \times \\
& \overline{\times \tan \gamma \sqrt{\tan ^{2} \gamma+1+\tan ^{2} \beta}}=B \text {. }
\end{aligned}
$$

$h$ - the distance from the lower edge of the wedge (from the zone of the uncultivated soil layer) to the contact point $K_{1}$ (fig. 1 ); $\varepsilon$ - coefficient of speed recovery after impact; $t_{y \partial \text {. }}$-impact duration, which can only be determined experimentally.

According to [9] $t_{y \partial .} \approx 0,6 \cdot 10^{-2} \mathrm{~s}$.

$f$-dynamic coefficient characterizing the properties of body surfaces that collide.

Angles $\alpha, \beta, \gamma, \delta, \psi$ are shown in fig. 1.

From expression (5) can be determined at a given amplitude of the desired circular frequency of the vibrations of the screed under conditions of not breaking the root:

$$
\omega=\frac{1}{a \cdot \tan \beta}\left(\frac{\left[M_{32}\right] t_{y \partial .}}{A \cdot B \cdot h \cdot m(1+\varepsilon)}-V_{\text {п }} \cdot \tan \gamma\right) .
$$

Then the vibrating frequency of the working device in hertz will be equal to:

$$
v=\frac{1}{2 \pi \cdot a \cdot \tan \beta}\left(\frac{\left[M_{32}\right] t_{y \partial .}}{A \cdot B \cdot h \cdot m(1+\varepsilon)}-V_{\text {п }} \tan \gamma\right) .
$$

On the basis of the developed theory of shock interaction of the vibratory digging out working device on a root crop it is possible to define a wide enough spectrum of admissible frequencies of vibrations of a working device on conditions not of breaking of root crops at various values of constructive and kinematic parameters of vibratory digging out working device.

To perform the calculation you need to specify the values of some parameters included in the expression

We will consider the specified structural parameters of the trihedral wedges of the digging working device, in particular the angles $\gamma$ and $\beta$ (fig. 1), $\gamma=14^{\circ} \ldots 15^{\circ}, \beta=50^{\circ} \ldots 55^{\circ}$.

Dynamic coefficient of friction of steel on the root surface accept $f=0,45$ [4]. With some approximation, we will consider that the angle $\psi=45^{\circ}$.

Distance of the point $K_{1}$ shock contact up to the lower edge of the wedge (up to the unfreezed soil layer) $h=0,05 \mathrm{~m}$.

Accept the speed recovery factor after impact $\varepsilon=0,72$. 
Allowable bending moment $\left[M_{3 \mathrm{r}}\right]$ shall be determined on the basis of an expression known from the material resistance rate:

$$
\left[M_{32}\right]=[\sigma]_{\partial .} \frac{\pi\left(D_{\kappa}-2 z \cdot \tan \gamma_{\kappa}\right)^{3}}{32} .
$$

where $[\sigma]_{\partial .}$ time resistance of root bending under dynamic load, $\mathrm{Pa} ; D_{k}$ - root diameter, $\mathrm{m} ; \gamma_{k}$ - root conicity angle, deg.; $z$ - working device depth in the ground, $\mathrm{m}$.

According to [4], $D_{k}=67 \ldots 122 \mathrm{~mm}, \gamma_{\kappa}=9^{\circ} \ldots 18^{\circ},[\sigma]_{\partial .}=1,15 \cdot 10^{6} \Pi \mathrm{la}$.

Accepted for calculation $D_{k}=100 \mathrm{~mm}, \gamma_{\kappa}=15^{\circ}$.

An important structural parameter in determining the impact interaction is the mass of the working device, raised to the point of impact. This is a part of the mass of the working device that directly takes part in the impact process. An approximate set of values of composite masses is obtained at given ranges of amplitudes and frequencies of oscillations of working elements, as well as velocities of progressive motion, which will be used in experimental studies. These are the following ranges of values of the mentioned parameters:

- working device vibration amplitude $a=8 \ldots .24 \mathrm{~mm}$;

- working device oscillation frequency $v=7,5 \ldots 20,3 \mathrm{~Hz}$;

- progressive speed of the digger $V_{\Pi}=1,4 \ldots 2,2 \mathrm{~m} \cdot \mathrm{s}^{-1}$.

With a view to (9) there is a view for the browse of green space:

$$
m=\frac{\left[M_{\text {зг }}\right] t_{\text {уд }}}{A \cdot B \cdot h(1+\varepsilon)\left(2 v \cdot \pi \cdot a \cdot \tan \beta+V_{\Pi} \cdot \tan \gamma\right)}
$$

The value of the total mass is obtained as a function of the oscillation frequency of the working body and the speed $V_{\Pi}$ of the progressive motion of the digger, ie $m=m\left(v, V_{\Pi}\right)$.

Thus, the calculated values of the summary masses will ensure that the root is not cracked during the impact interaction of specific values of stroke depth, amplitudes and frequencies of oscillations of the working body, as well as specific values of the progressive speed of the digger.

In this case, in addition to the set of summary masses values, we get the graphs of the function $m=m\left(v, V_{\Pi}\right)$ for different versions of the stroke depth and vibration amplitude values of the vibrating screed and the corresponding contour diagrams.

Since the working depth of the Vikopuvalnyh working bodies in most cases does not exceed $0.10 \mathrm{~m}$ [9], let us give an example of a calculation option for $z=0.10 \mathrm{~m}$ and amplitudes $a=0.016 \mathrm{~m}$. For this case, the graph function $m=m\left(v, V_{\Pi}\right)$ and corresponding contour diagram are shown in fig. 2 .

In this case, the frequencies vary within $v=7.5 \ldots 20.3 \mathrm{~Hz}$, and the digger's forward motion speed is within $V_{\Pi}=1.4 \ldots 2.2 \mathrm{~m} \cdot \mathrm{s}^{-1}$.

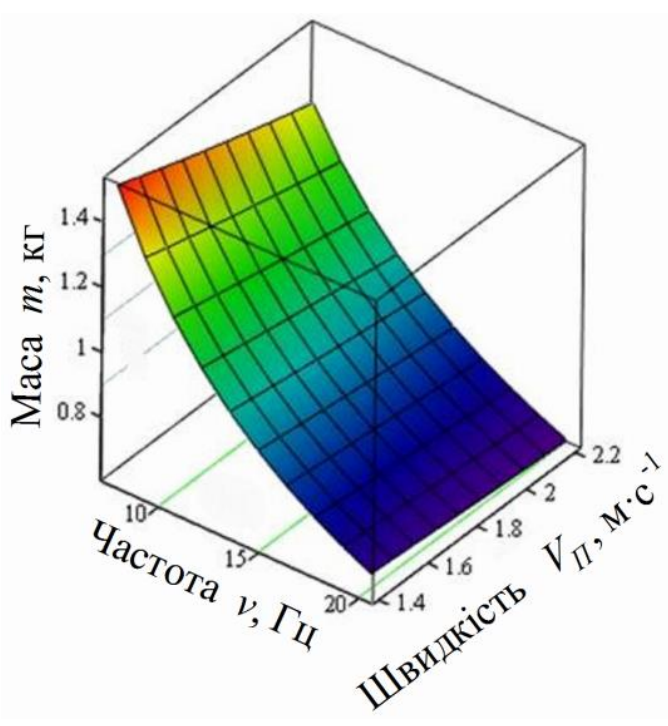

a

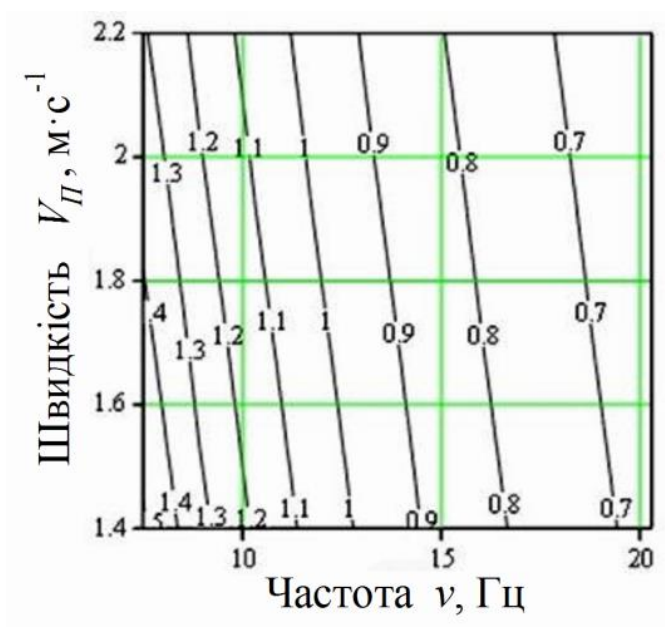

6

Fig. 2. Surface (a) and contour diagram (b) of the values of the mass of the working device consolidated to the point of impact $m\left(v, V_{\Pi}\right)$, $\mathbf{k g}$ (depth of the working device $z=0.10 \mathrm{~m}$; amplitude of oscillations $a=0.016 \mathrm{~m}$ 
The resulting graph clearly reflects the tendency of reducing the total mass of the working body with increasing frequency of oscillation and speed of progressive movement of the digger. So, within the limits of change of frequency of fluctuations and speed of progressive movement of the digger, presented in this graph, the given mass of a working body changes within $1.51 \ldots 0.63 \mathrm{~kg}$.

Thus, these calculations have provided an opportunity to obtain a fairly wide range of values of composite masses of the working body. Of course, the development of a specific vibratory vicopolubular working device deals with the specific value of the composite mass. However, using the results of the above calculations, we can always say that the kinematic mode of movement of the working device provides this reduced mass from the conditions of non-crushed root crops. Moreover, by selecting a specific value of the combined mass from the obtained spectrum of combined masses values (or close to it), one can calculate the values of admissible frequencies for a wider spectrum of amplitudes, depths of the working body stroke, velocities of progressive motion of the digger.

By expression (9) we calculate the permissible frequency of vibrations of the working device as a function of the speed of the progressive motion of the digger and the amplitude of vibrations of the working device, that is $v=v\left(V_{\Pi}, a\right)$. In this case, the speed of the progressive motion of the digger changes within the range of $1.4 \ldots 2.2 \mathrm{~m} \cdot \mathrm{s}^{-1}$, and amplitude - within $0.008 \ldots 0.024 \mathrm{~m}$.

Below is a graph of the function $v=v\left(V_{I}, a\right)$ and the contour diagram for the total mass of the working body $m=1.5 \mathrm{~kg}$ and its depth in the soil $z=0.10 \mathrm{~m}$ (fig. 3 ).

As can be seen from the graph above, the permissible frequency is very much dependent on the amplitude of the vibrations of the working device: with increasing amplitude of oscillations, the permissible frequency decreases sharply. It also decreases with increasing speed of progressive motion of the digger.

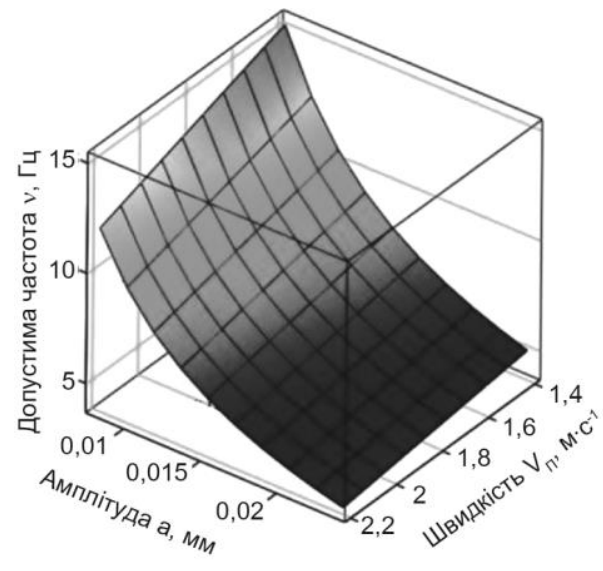

Fig. 3. Surface (a) and contour diagram (b) of the values of the allowable frequency of vibrations

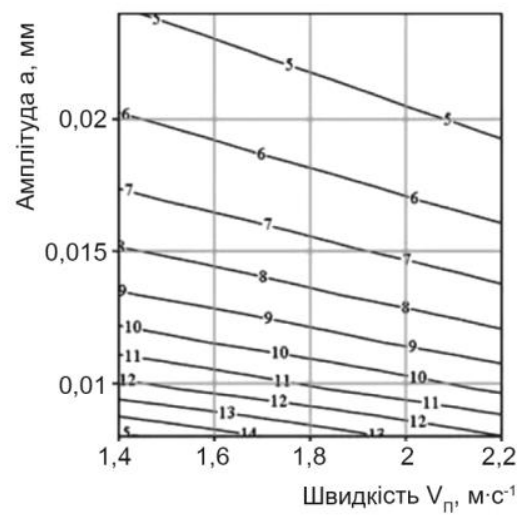

6 of the working device $v=v\left(V_{\Pi}, a\right)$, Hz,on condition that the roots are not slammed during their impact interaction with the working body (depth of the working body $z=0.10 \mathrm{~m}$; erected mass of the working body a $=1.5 \mathrm{~kg}$ )

Thus, at growth of amplitude of oscillations of a working body within the limits of $0.008 \ldots 0.024 \mathrm{~m}$ and the speed of progressive motion of the digger within the limits of $1.4 \ldots 2.2 \mathrm{~m} \cdot \mathrm{s}^{-1}$, the maximum permissible frequency varies within $15.7 \ldots 40 \mathrm{~Hz}$.

The above vibration frequency values of the vibrating organ are the maximum permissible frequency values from the conditions of non-slamming of the tail part of the root crop during shock interaction. Lower vibration frequency values will ensure the more shatterproofing of the tail part of the root crop.

It is quite obvious that the value of maximum permissible frequencies for the composite mass of the working body $m=1.5 \mathrm{~kg}$ the more meet the conditions of non-slaverying of the tail part of the root part for the lower values of the composite mass of the working body. Actually, the maximum permissible frequencies for the lower values of the working tool aggregate masses at the corresponding amplitudes and depths of the working tool stroke will be even higher.

Of course, the above values of admissible frequencies from the conditions of neslazlamuvannya tail part of the root at the impact interaction should be limited to the bottom conditions of the obligatory delight of each root of the vicopuvalnimi ploughshare of the working body.

Thus, the developed theory of shock interaction of the working body with the root crop fixed in the soil makes it possible with the help of PC to calculate a wide enough range of kinematic modes of operation of vibratory vicopuvalnyh working body taking into account its structural and technological parameters with the conditions of not breaking the root crop. 
Conclusions

According to the developed equivalent scheme and application of the general theory of impact, a mathematical model of the impact interaction of the working body with the root body in one point (asymmetric impact) is constructed, on the basis of which analytical expressions for determination of the maximum allowable frequency of oscillations of the working body and its mass reduced to the point of impact from the condition of non-slammering of the tail part of the root body at the specified interaction are obtained.

Spectrums of permissible masses of the working device, which are consolidated to the point of impact, permissible frequencies of vibrations of the working device and permissible velocities of progressive movement of the digger from the conditions of non-crushing of the root crops at impact taking into account the design parameters of vibratory vicopuvalnyh working device and physical and mechanical properties of sugar beet root crops have been determined.

At growth of frequency of oscillation of a working body within the limits of $7.5 \ldots 20.3 \mathrm{~Hz}$ and the speed of progressive motion of the digger within the limits of $1.4 \ldots 2.2 \mathrm{~m} \cdot \mathrm{s}^{-1}$ value of its mass reduced to the point of impact has a tendency to decrease and varies within $1.51 \ldots 0.63 \mathrm{~kg}$ with an amplitude of fluctuations of $0.016 \mathrm{~m}$.

Maximum permissible frequency of vibrations of the working device with increasing amplitude of its vibrations sharply decreases. It also decreases with the growth of the speed of progressive motion of the digger. Thus, for the total mass of the working device $1.5 \mathrm{~kg}$ and depth of its stroke in the soil $0.10 \mathrm{~m}$, with the growth of the amplitude of the oscillations of the working device within $0.008 . .0 .024 \mathrm{~m}$ and speed of its forward motion digger within the limits of $1.4 . .2 .2 \mathrm{~m} \cdot \mathrm{s}^{-1}$, the maximum permissible frequency varies within the limits of 15.7...4.0 Hz. For a depth of stroke of the working device $0.08 \mathrm{~m}$ - within the limits of 33.0...10.0 Hz.

\section{References}

1. Vasilenko, P.M., Pogorelyy, L.V., \& Brey, V.V. (1970). Vibratsionnyy sposob uborki korneplodov [Vibration method of harvesting root crops]. Mechanization and electrification of socialist agriculture, 2 , 9-13. [in Russian].

2. Bulhakov, V.M., Holovach, I.V., (2003). Teoriia vibratsiinoho vykopuvannia koreneplodiv [Theory of vibratory digging of roots]. Collection of scientific works of the National Agrarian University «Mechanization of agricultural production», XIV, 34-86. [in Ukrainian].

3. Holovach, I.V. (2006). Teoriia bezposerednoho vyluchennia koreneplodu z gruntu pry vibratsiinomu vykopuvanni [The theory of direct extraction of root crops from the soil by vibration excavation]. Bulletin of the Petro Vasylenko Kharkiv National Technical University of Agriculture. Collection of scientific works, 44(2), 77-100. Kharkiv: KhNTUSH. [in Ukrainian].

4. Pogorelyy, L.V., Tatyanko, N.V., Brey, V.V. i dr. (Pogorelyy L.V. (Ed.)). (1983). Svekloubochnye mashiny (konstruirovanie i raschet) [Beet-harvesting machines (design and calculation)]. Kiev: Tekhnika. [in Russian].

5. Pogorelyy, L.V., \& Tatyanko, N.V. (2004). Sveklouborochnye mashiny (istoriya, konstruktsiya, teoriya, prognoz) [Beet harvesters (history, design, theory, forecast)]. Kiev: Feniks. [in Russian].

6. Zaika P.M. (1992). Izbrannye zadachi zemledelcheskoy mekhaniki [Selected tasks of agricultural mechanics]. Kiev: USKhA. [in Russian].

7. Zaltzman, A., \& Schmilovitch, Z. (1985). Evolution of the potato fluidized bed medium separator (Conference Paper). American Society of Agricultural Engineers.

8. Karwowski, T. (1982). Teoria i konstrukcja maszyn rolniczych. T. 3. Warszawa: PWRiL. (In Poland).

9. Ichiki, H., Nguyen, Van N., \& Yoshinaga, K. (2013). Stone-clod separation and its application to potato cultivation in Hokkaido. Biooriented Technology Research Advancement Institution, Engineering in Agriculture, Environment and Food, 6(2), 77-85.

10. Panovko, Ya.G. (1990). Osnovy prikladnoy teorii kolebaniy $i$ udara [Foundations of the applied theory of vibrations and impa]. Leningrad: Politekhnika. [in Russian].

11. Panovko, Ya.G. (1985). Vvedenie $v$ teoriyu mekhanicheskogo udara [Introduction to the theory of mechanical impact]. Moskva: Nauka. [in Russian].

12. Butenin, N.V., Lunts, Ya.L., \& Merkin, D.R. (1985). Kurs teoreticheskoy mekhaniki [Theoretical Mechanics Course]. T. II. Dinamika. Moskva: Nauka. [in Russian]. 